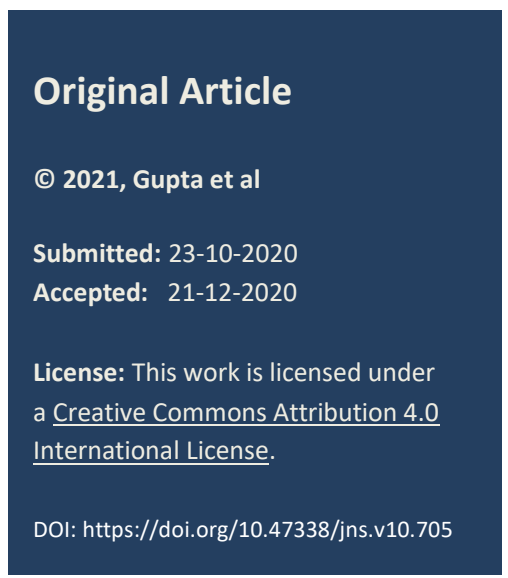

\title{
Oxidized regenerated cellulose gauze as a hemostat in infantile hypertrophic pyloric stenosis
}

\author{
Rahul Gupta, ${ }^{1 *}$ Anu Bhandari, ${ }^{2}$
}

1 Department of Paediatric Surgery, SMS Medical College, Jaipur, Rajasthan, India

2 Department of Radiodiagnosis, SMS Medical College, Jaipur, Rajasthan, India

Correspondence*: Dr. Rahul Gupta, Assistant Professor, Department of Paediatric Surgery, SMS Medical College, Jaipur, Rajasthan India. E-mail: meetsurgeon007@gmail.com

\author{
KEYWORDS \\ Hemostat, \\ Infantile hypertrophic pyloric \\ stenosis, \\ Outcome, \\ Oxidized regenerated cellulose \\ gauze, \\ Pyloromyotomy, \\ Ramstedt
}

\begin{abstract}
Background: The Ramstedt pyloromyotomy is a standard procedure for infantile hypertrophic pyloric stenosis (IHPS). However, continuous postoperative bleeding may occur from the pyloromyotomy site without the use of any hemostatic management. We aim to analyze the pre-operative and post-operative hemogram values with and without the use of oxidized regenerated cellulose gauze as a hemostat in IHPS.
\end{abstract}

Methods: A prospective study performed from January 2019 to March 2020. The patients were randomly distributed by chit method into two groups: Group A (Control) without the use of hemostat and Group B (Case) with oxidized regenerated cellulose gauze as a hemostat.

Results: There were 26 patients with 19 males and 7 females. There were 13 patients in Group A and 12 in Group B; while one patient succumbed before surgery. Ramstedt's pyloromyotomy was performed in $25(96.16 \%)$ patients. A total of $7(28 \%)$ postoperative complications were recorded in our patients. One patient in group A with intraperitoneal blood collection required blood transfusion for anemia caused by peritoneal bleeding. There was one postoperative death (group A). Significant statistical differences between preoperative and postoperative RBC $(106 / \mathrm{mm} 3)$, hemoglobin $(\mathrm{g} / \mathrm{dl})$, and hematocrit $(\%)$ levels were observed in group A but insignificant differences among the values in group B.

Conclusions: We recommend that oxidized regenerated cellulose should be applied to the pyloromyotomy site to minimize perioperative bleeding associated with the Ramstedt procedure. It appears to be a safe, easily available, easy to use, and effective hemostatic agent available for IHPS.

\section{INTRODUCTION}

Ramstedt developed the pyloromyotomy procedure for infantile hypertrophic pyloric stenosis (IHPS).[1] This serendipitous discovery has stood the test of over a century.[1,2] It has been established as a safe, effective, and standard procedure.[1,2] Occasional complications are duodenal perforation and prolonged postoperative vomiting due to incomplete myotomy.[2,3] Also, continuous postoperative bleeding may occur from the pyloromyotomy site.[3] Rarely, blood transfusion or reoperation was required to control postoperative pyloromyotomy-site bleeding.[3,4] Hemostatic material is rarely studied for pyloromyotomy and oxidized regenerated cellulose has not been used previously to the best of our knowledge. $[4,5]$ We are shar- ing our experience with the use of oxidized regenerated cellulose along with a mini-review of pertinent literature. The main aim is to analyze the pre-operative and postoperative hemogram values with and without the use of oxidized regenerated cellulose gauze as a hemostat in IHPS.

\section{METHODS}

A single-center, prospective study was performed from January 2019 to March 2020. The study included all patients with IHPS admitted to our tertiary care institute. As per the International Classification of Diseases Code (ICD-10-AM) patients of IHPS (Q40.0) were evaluated. The patients were randomly divided by chit method into two groups with Group A and B. Group A (Control) without the use of hemostat and Group B 
(Case) with oxidized regenerated cellulose gauze (Surgicel $\left.{ }^{\circledR}\right)$ as a hemostat applied to the incised region of pylorus during pyloromyotomy. Surgicel ${ }^{\circledR}$ is a bioabsorbable hemostatic mesh that is frequently packed around the oozing surgical bed.

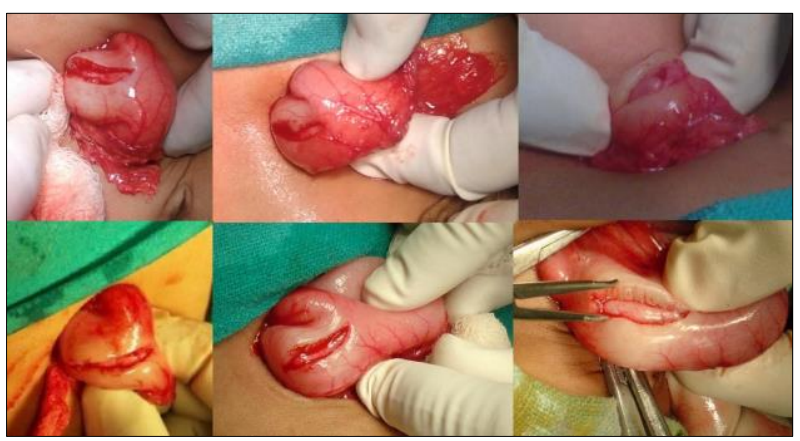

Figure 1: Intraoperative photographs showing completed pyloromyotomy with split muscle and pyloric mucosa below it.

Technique: A $2.5 \mathrm{~cm}$ transverse skin incision was made midway between the xiphoid and umbilicus on the right upper abdomen. All layers of the abdominal wall including rectus sheath, muscle, and peritoneum were cut using electrocautery. Babcock forceps were gently applied to the distal pylorus; with gentle traction, the olive was delivered into the wound, firmly grasped and held between the thumb and index finger. Pyloric muscle and serosa were cut over the anterosuperior avascular area, parallel with the long axis of the lumen by a scalpel. The muscle was split with Benson's pyloric spreader (Fig.1). In Group A, abdominal closure was done without the use of hemostat; while in Group B, oxidized regenerated cellulose was used. A single patch (approximately $2.5 \times 2.5 \mathrm{~cm}$ ) was placed over the incised region of the pylorus (target area) before abdominal wall closure (Fig.2). Closure of the incision was made with interrupted absorbable sutures for each layer. The dressing was applied with help of adhesive tapes. Postoperative oral intake started as per standard protocol. All procedures were performed after correcting dehydration and electrolyte imbalances. Same postoperative care including antibiotics was given to the patients in each group.

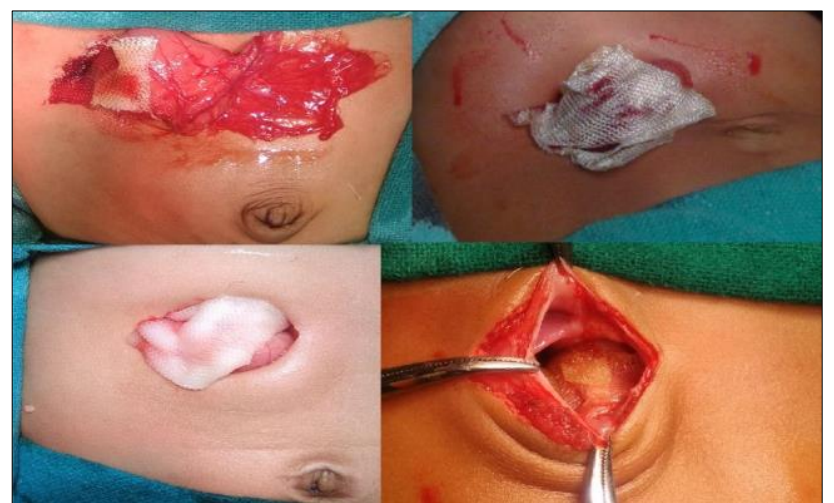

Figure 2: Oxidized regenerated cellulose gauze patch (approximately $2.5 \times 2.5 \mathrm{~cm}$ ) placed over the incised region of the pylorus (target area).
The clinical, operative records and other details of these patients were analyzed. Charts were reviewed according to age at presentation, sex, complaints and their duration, clinical findings, investigations are undertaken, preoperative and postoperative hemoglobin, hematocrit, blood counts, operative procedure, intraoperative and postoperative complications, and final outcomes. Safety of the Surgicel ${ }^{\circledR}$ was assessed from the time of its use during the surgery to 3 months follow-up.

Preoperative and postoperative changes in hemoglobin $(\mathrm{Hb})$, hematocrit (Hct), and red blood cell count (RBC) were compared between groups A and B. All figures were expressed as mean value \pm standard deviation. The t-test (test of significance) was applied for comparison of preoperative and postoperative values. Unpaired t-test was applied for comparison of Group A and Group B. A p-value of less than 0.05 was considered significant. All statistical data analyses were obtained with SPSS version 10.0 for Windows.

\section{RESULTS}

There were 26 patients with 19 males and 7 females $(\mathrm{M}: \mathrm{F}=2.71: 1)$. There were 13 patients in Group A and 12 in Group B; while one patient succumbed preoperatively. Age ranged from 16 days (youngest) to 101 days (oldest) with a median value of 40.5 days. Among age groups, $42.31 \%$ (11) of the patients were between 4 to 6 weeks; three $(11.54 \%)$ patients were less than 4 weeks. The weight of the patient ranged from $2000 \mathrm{gm}$ to $4800 \mathrm{gm}$ with a median value of 3300 gm. Approximately, $15.38 \%$ (4) of the patients were below $2500 \mathrm{gm}$ at the time of admission. The Mean weight at presentation was $3330 \mathrm{gm}$, while the mean age at admission was 46 days. The weight, sex, and age variables were comparable in Group A and Group B.

Projectile vomiting was the chief complaint in all the patients; the duration of symptoms ranged from 3 to 30 days. Lump (olive) was palpable in 53.84\% (14) patients; abdominal ultrasound examination was diagnostic in $100 \%$ (26) cases. The average size of the olive was 5.04 x $20.29 \mathrm{~mm}$. The contrast study was not performed in any of the cases.

Nutritional disturbance leading to loss of pad of fat and anemia was present in $38.46 \%$ (10) infants. Leukocytosis (TLC $>11,000 / \mathrm{mm} 3$ ) was also appreciated in $26.92 \%$ (7) cases in our series. Deranged coagulation profile (INR>1.5) was present in $7.69 \%$ (2) infants. A deranged coagulation profile $(I N R>1.50)$ was present in one patient in each group. INR $=1.95$ was seen in one patient in Group B and INR $=1.59$ in the other patient (postoperative mortality) in Group A. Metabolic disturbance with hyponatremia was present in $42.30 \%$ (11) infants, hypokalemia $23.07 \%$ (6), hypochloremia $23.07 \%$ (6) along with dehydration and deranged renal functions were present in $23.07 \%$ (6). 
A Severe metabolic disturbance was present in $3.84 \%$ (1) patients. Correction of dyselectrolytemia and dehydration was performed in all cases. In the majority $(96.16 \%)$ of infants, preoperative optimization was achieved, while 1 (3.84\%) patient succumbed due to metabolic derangement before contemplating operative intervention thus excluded from the study.

In our study, Ramstedt's pyloromyotomy was performed in 96.16\% (25: Group A=13, Group B=12) patients. No intraoperative complications were encountered in any of the patients. A total of $7(28 \%)$ postoperative complications were recorded including postoperative vomiting (2; Group $\mathrm{A}=1$, Group $\mathrm{B}=1$ ), ileal perforation (1; Group A), intraperitoneal blood collection (1; Group A), seroma formation (2; Group $A=1$, Group $B=1)$, mortality (1; Group A). No patient in our study suffered from persistent vomiting for more than 5 days (requiring re-evaluation for any incomplete myotomy).

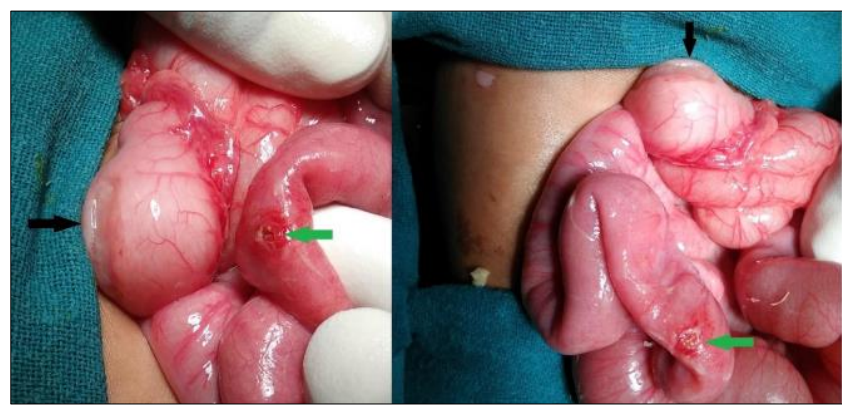

Figure 3: Intraoperative photographs showing pyloromyotomy scar represented by a faint furrow (black arrow) and mid-ileal perforation (green arrow).

One patient in our study who developed ileal perforation, presented after discharge with features of peritonitis ( 5 days postoperatively); the diagnosis was established intra-operatively during the second surgery. The cause of ileal perforation was not known, but likely due to iatrogenic injury. The trace of pyloromyotomy was represented by a faint furrow with a light yellow white, slightly edematous serosa (Fig.3). One patient in group A with intraperitoneal blood collection (above mentioned) required blood transfusion for anemia caused by pyloromyotomy-site bleeding. The diagnosis was established by ultrasound abdomen (Fig.4). In cases with postoperative vomiting, ultrasounds were performed to diagnose complications or those related to the placement of Surgicel ${ }^{\circledR}$, which were normal (Fig.5).

The exact cause of post-operatively mortality could not be established. The patient died within 24 hours postoperatively and purported to be either due to anesthesia-related post-operative apnea, hemodynamic shock, or respiratory arrest. Also, the cause of preoperative death in one of the patients in the study was pre-existing dehydration, hemodynamic shock, and electrolyte imbalance.

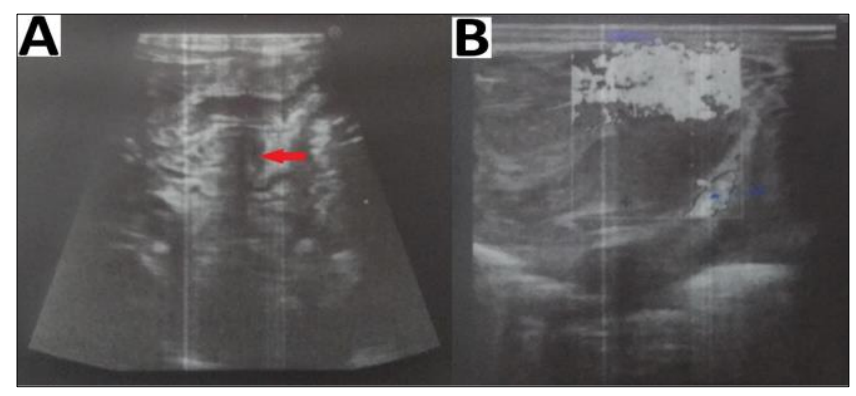

Figure 4: Photographs showing abdominal ultrasound scans performed after pyloromyotomy (Group A) with intraperitoneal blood collection (red arrow) around the pylorus (red arrow; A) and collection in Morrison's pouch (B).

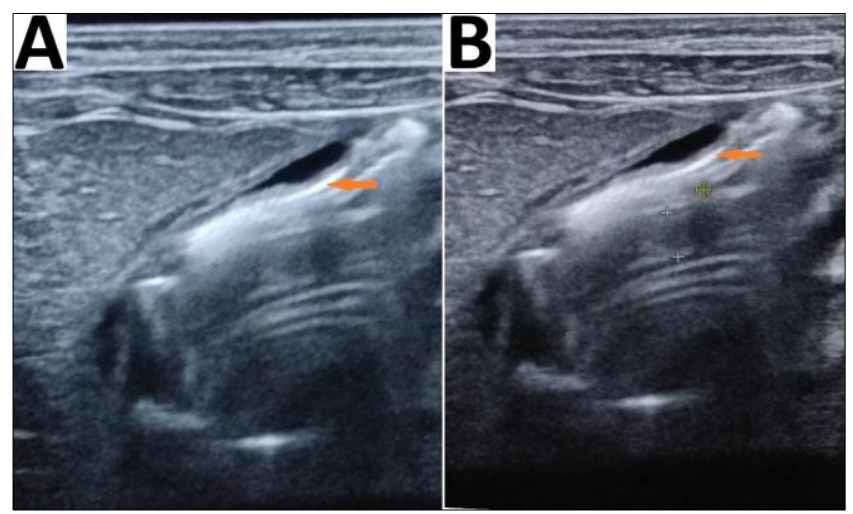

Figure 5: Photographs showing abdominal ultrasound scans performed after pyloromyotomy (Group B) with oxidized regenerated cellulose gauze patch represented by hyperechogenic line (red arrow); minimal fluid $(+)$ around the pyloromyotomy site is also present (B)

Significant statistical differences between preoperative and postoperative $\mathrm{RBC}(106 / \mathrm{mm} 3)$ were observed in group A $(4.20 \pm 0.55 ; 3.43 \pm 0.59, \mathrm{p}<0.01)$, but insignificant differences were present in group B (4.15 \pm $0.46 ; 3.93 \pm 0.53, \mathrm{p}>0.05)$. Similarly, $\mathrm{Hb}(\mathrm{g} / \mathrm{dl})$ levels significantly decreased in group A $(12.72 \pm 1.74 ; 9.86$ $\pm 1.25, \mathrm{p}<0.01)$ but not in group B (12.62 \pm 1.56 ; $11.87 \pm 1.72, \mathrm{p}>0.05)$. Also, hematocrit (\%) significantly decreased in group A $(39.5 \pm 4.58 ; 30.58 \pm$ $4.85, \mathrm{p}<0.01)$ but not in group B $(36.59 \pm 4.33 ; 34.05$ $\pm 5.24, \mathrm{p}>0.05)$ as shown in Table 1 . The differences in preoperative and postoperative values of $\mathrm{RBC}, \mathrm{Hb}$, and hematocrit between group A and group B were also evaluated by unpaired t-test. The difference in mean fall of $\mathrm{Hb}(\mathrm{g} / \mathrm{dl})$, hematocrit $(\%)$, and $\mathrm{RBC}$ $(106 / \mathrm{mm} 3)$ between group A and group B were statistically ( $<<0.01$ ) significant (Table 1$)$.

\section{DISCUSSION}

IHPS (1-4 per 1000 live births) was first described as a disease entity by Danish Pediatrician Harald Hirschsprung (1888).[2,6] Gastroenterostomy was the accepted surgical procedure till Fredet (1908) devised the technique of splitting the pylorus muscle longitudinally and closing it in the transverse plane.[2,6] In 1912, Ramstedt modified Fredet's operation by omitting the closure in the transverse plane of the longitudinally split pyloric muscle. The operation is re- 
ferred to as "Fredet-Ramstedt pyloromyotomy" or commonly as the "Ramstedt pyloromyotomy".[2,6,7] IHPS is more common in males than in females $(4: 1$ to $6: 1) \cdot[2,8,9]$ In our study the ratio was a little less (2.71: 1$)$ owing to smaller study group and regional variations.

Table 1: A Comparative evaluation of preoperative and postoperative blood values in Group A and Group B; $[\mathrm{RBC}=$ red blood count; SD = Standard Deviation; $p$ value $<0.05$ is Statistically significant]

\begin{tabular}{|c|c|c|c|c|}
\hline $\begin{array}{l}\text { Group A (n=13) } \\
\text { Characteristics }\end{array}$ & Preoperative values & Postoperative values & $\begin{array}{l}\text { p-value } \\
\text { (Unpaired t-test) }\end{array}$ & $\begin{array}{l}\text { The difference in Preoperative } \\
\text { and Postoperative values }\end{array}$ \\
\hline $\begin{array}{l}\text { Haemoglobin } \pm \text { SD } \\
\text { (g/dl) }\end{array}$ & $\begin{array}{l}12.72 \pm 1.74 \\
(\text { Median }=12.4)\end{array}$ & $\begin{array}{l}9.86 \pm 1.25 \\
(\text { Median }=10.1)\end{array}$ & $p<0.01$ & $2.86 \pm 1.58$ \\
\hline $\begin{array}{l}\text { Haematocrit } \pm \text { SD } \\
(\%)\end{array}$ & $\begin{array}{l}39.5 \pm 4.58 \\
(\text { Median }=39.6)\end{array}$ & $\begin{array}{l}30.58 \pm 4.85 \\
(\text { Median }=30.4)\end{array}$ & $\mathrm{p}<0.01$ & $8.91 \pm 5.18$ \\
\hline $\begin{array}{l}\text { RBC } \pm \text { SD } \\
\left(10^{6} / \mathrm{mm}^{3}\right)\end{array}$ & $\begin{array}{l}4.20 \pm 0.55 \\
(\text { Median }=4.23)\end{array}$ & $\begin{array}{l}3.43 \pm 0.59 \\
(\text { Median }=3.51)\end{array}$ & $\mathrm{p}<0.01$ & $0.76 \pm 0.59$ \\
\hline $\begin{array}{l}\text { Group B (n=12) } \\
\text { Characteristics }\end{array}$ & Preoperative values & Postoperative values & p value & Difference \\
\hline $\begin{array}{l}\text { Haemoglobin } \pm \text { SD } \\
\text { (g/dl) }\end{array}$ & $\begin{array}{l}12.62 \pm 1.56 \\
(\text { Median=12.5) }\end{array}$ & $\begin{array}{l}11.87 \pm 1.72 \\
(\text { Median }=11.8)\end{array}$ & $p>0.05$ & $0.56 \pm 0.56$ \\
\hline Haematocrit \pm SD & $\begin{array}{l}36.59 \pm 4.33 \\
(\text { Median }=36.85)\end{array}$ & $\begin{array}{l}34.05 \pm 5.24 \\
(\text { Median }=34.75)\end{array}$ & $\mathrm{p}>0.05$ & $2.54 \pm 2.33$ \\
\hline $\begin{array}{l}\text { RBC } \pm \text { SD } \\
\left(10^{6} / \mathrm{mm}^{3}\right)\end{array}$ & $\begin{array}{l}4.15 \pm 0.46 \\
(\text { Median }=4.215)\end{array}$ & $\begin{array}{l}3.93 \pm 0.53 \\
(\text { Median }=4.13)\end{array}$ & $\mathrm{p}>0.05$ & $0.22 \pm 0.17$ \\
\hline
\end{tabular}

In our series, most $(73 \%)$ cases presented between 3 to 8 weeks. Late presentation (27\%) beyond this duration in our series was due to a lack of awareness and ignorance among families as they considered vomiting as a minor symptom.[10] Youngest patient as small as 3 days and late presentation (207 days) has also been reported.[10]

The patient typically presents with progressive nonbilious projectile vomiting between 2 to 8 weeks of life. $[6,8,10]$ Traditionally, diagnosis is made by palpation of the "pyloric olive" - "the peanut under the blanket" (53.84\% in our series) along with visible gastric peristalsis (from left to right when nursing).[2,10] Conventionally, pyloric muscle thickness more than 3 $\mathrm{mm}$ on ultrasonography is considered diagnostic (100\% in our series) of IHPS. In our study, associated anomalies were not elicited, while in a large recent series they were present in $6.9 \%$ of patients.[8] Hypochloremic, hyponatremic, hypokalemic metabolic alkalosis results from loss of large amounts of gastric hydrochloric acid. The severity of metabolic derangement depends upon the duration of symptoms and time of presentation.[4,6]

Open Ramstedt's operation encompasses pyloromyotomy over the avascular anterosuperior surface of the pylorus. During the muscle-splitting procedure if this avascular area is carefully selected then bleeding, as a rule, is minimal. Bleeding from the cut edge of the pyloromyotomy occurs due to venous congestion caused by tension and traction on the pylorus and stomach. It is described in the literature, that when the pylorus is returned to the abdominal cavity, bleeding spontaneously diminishes. Thus, hemostasis with either suture ligation and/or cautery is not considered essential.[3] Also, cautery coagulation may result in burn injury to the submucosal layer and perforation.[3] If bleeding persists even after the pylorus is replaced into the peritoneal cavity, then warm moist packs held with continuous pressure for three to five minutes over the myotomy is done.[7] Transfixation ligatures have been advised if this fails.[7] Mucosal perforation is a rare intraoperative complication.

As per the literature, Ramstedt's operation does not require any special hemostatic management. [6,7] But as per our experience and few researchers, continuous postoperative bleeding may occur from the pyloromyotomy site without the use of any hemostatic management.[3] Continued bleeding can occur in the setting of undetected coagulopathy. Literature suggests that rarely, blood transfusion or reoperation may be required due to postoperative pyloromyotomysite bleeding.[3] A Japanese study suggested the use of hemostat in the form of fibrin glue for the Ramstedt's operation.[3] They used fibrin adhesive that works on the principle of physiological blood coagulation. A study also described the application of topical thrombin and microfibrillar collagen (Avitene) as a hemostat for pyloromyotomy.[5] A study performed over 7 years, published in 1946 clearly indicated postoperative transfusions of whole blood indicated by the RBC count and hemoglobin values in IHPS. The study though does not mention the exact number of patients out of 380 requiring blood transfusion but indirectly suggests that there is a blood transfusion requirement owing to postoperative bleeding from the pyloromyotomy site.[4]

In our study, only one patient in group A with intraperitoneal blood collection required blood transfusion for anemia. Also, only one patient in the study from 
Japan in group A (without hemostat) required a blood transfusion.

There are only few studies that have calculated preoperative and postoperative hemoglobin / RBC counts in IHPS.[3] To the best of our knowledge, the use of oxidized regenerated cellulose in Ramstedt's operation has not been evaluated to date. Our study fulfills both the aforementioned objectives.

Hemostatic agents are used for the treatment of local bleeding in addition to the conventional methods using suture.[11-13] Several hemostatic materials available are gelatines, collagens, oxidized cellulose, fibrin, thrombin, polysaccharides, hydrogel-based hemostats, and combinations of the above constituents.[13]

Oxidized cellulose was first introduced by Frantz in 1942.[14] Oxidized regenerated cellulose (lower molecular weight and various cellulose origin) was launched in 1960. It is created by decomposing wood pulp and then regenerating the cellulose by manufacturing continuous cellulose fibers. It is branded as Surgicel ${ }^{\circledR}$ by Johnson \& Johnson ${ }^{\circledR}$. Chemically, it is a sheet of oxidized cellulose polyanhydroglucuronic acid.[15] It is used as a knitted fabric that can be cut to match the size of the area that needs hemostasis. It is absorbable and does not stick to instruments facilitating easier handling.

Oxidized regenerated cellulose gauze is frequently placed on the surgical bed as a hemostatic pack for controlling capillary, venous, or suture line bleeding intra and postoperatively. It is hypothesized that it works by (a) a physical effect i.e. as it absorbs blood, gets saturated, and gently swells into a brownishblack gelatinous mass which aids in the formation of a clot; (b) An alteration of normal physiologic processes. As it has a low $\mathrm{pH}$; causes red blood cell lysis which may trigger hematin formation thus accelerating clotting. The capacity of tissues to absorb Surgicel ${ }^{\circledR}$ makes it a valuable hemostatic agent to surgeons. Its biodegradation starts within 24 hours and its absorption complete in 4-8 weeks. [11,13]

The risks associated with these agents are external compression due to its hygroscopic nature, granuloma formation, pseudo abscess, paraplegia, prolonged drainage and, risk of fever.[11,16] Other complications are coronary ischemia (due to periaortic compression) and nerve injury (compression when left in and around bony canals) due to its hygroscopic nature.[13-17] No patient in Group B suffered from any complications related to Surgicel ${ }^{\circledR}$.

A Japanese study concluded that there were statistically significant differences between preoperative and postoperative RBC levels, hemoglobin and hematocrit levels in the group without hemostat but not in the group with a hemostat.[3] Our study also confirms that the use of oxidized regenerated cellulose resulted in statistically significant less postoperative blood loss. Our study was done prospectively while the earlier studies were retrospective.[3] Our study was randomized, i.e. in our study, the patients were randomly distributed by chit method into control and case groups. The number of patients in both groups in our study was comparable, while in the previous study the difference in the number of patients was significant.[3]

The difference in preoperative and postoperative values in group A (Control) versus group B (Case) was statistically significant. We recommend gentle placement of oxidized regenerated cellulose over the divided muscle, rather than wrapping it around the pylorus to control the bleeding. Wrapping should not be done as it may be associated with luminal compression and failure of the procedure. Also, the smallest amount of Surgicel should be used, which has also been recommended by other researchers.[18] There were more complications in Group A than in Group B. With a total of $28 \%(7 / 25)$ complication rate, Group A had $20 \%(5 / 25)$. Major complications like intraperitoneal blood collection (1), mortality (1), and ileal perforation (1) were all observed in Group A and none in Group B.

Limitations of the study include a small sample size which may have influenced the final results and conclusions that were made in the study. A randomized controlled trial with statistically calculated sample size can validate the results of our study. Results and figures from our pilot study should be used to design larger confirmatory studies.

\section{CONCLUSION}

Our study detected significant statistical differences between preoperative and postoperative $\mathrm{RBC}, \mathrm{Hb}$, and hematocrit values in Group A (control) but insignificant differences among these values in Group B (Case) with the use of oxidized regenerated cellulose. We recommend that oxidized regenerated cellulose should be applied to the pyloromyotomy site to minimize perioperative bleeding. Gentle placement of oxidized regenerated cellulose should be done over the divided muscle, rather than wrapping it around the pylorus. It appears to be a safe, easily available, easy to use, and effective hemostatic agent for suspected perioperative peritoneal bleeding for IHPS.

Acknowledgements: We are sincerely thankful to Dr L.D. Agrawal, Dr Arun K. Gupta, faculty members, residents, and nursing staff of department of Paediatric Surgery, SMS Medical College, Jaipur, for helping us in this endeavor.

Conflict of Interest: Authors have no conflict of interest.

Source of Support: Nil 
Consent to Publication: Author(s) declared taking informed written consent for the publication of clinical photographs/material (if any used), from the legal guardian of the patient with an understanding that every effort will be made

\section{REFERENCES}

1. Handu AT, Jadhav V, Deepak J, Aihole JS, Gowrishankar, Narendrababu M, et al. Laparoscopic pyloromyotomy: Lessons learnt in our first 101 cases. J Indian Assoc Pediatr Surg. 2014; 19:213-7.

2. Raveenthiran V. Centennial of pyloromyotomy. J Neonatal Surg. 2013; 2:8

3. Yamazaki Y, Yoshida T, Mizuno R, Yuno S, Hara A, Yoshizawa J, et al. Hemostasis for the Ramstedt procedure: use of a fibrin adhesive. Pediatr Surg Int. 1994; 9:455-6.

4. Ladd WE, Ware PF, Pickett LK. Congenital hypertrophic pyloric stenosis. JAMA. 1946; 131:647-51.

5. Walker K, Halliday R, Holland AJA, Karskens C, Badawi N. Early developmental outcome of infants with infantile hypertrophic pyloric stenosis. J Pediatr Surg. 2010; 45:2369-72.

6. Hernanz-Schulman M. Infantile hypertrophic pyloric stenosis. Radiol. 2003; 227:319-31. Available from: https://doi.org/10.1148/radiol.2272011329.

7. Perger L, Fuchs JR, Komidar L, Mooney DP. Impact of surgical approach on outcome in 622 consecutive pyloromyotomies at a pediatric teaching institution. J Pediatr Surg. 2009; 44:2119.

8. Chalya PL, Manyama M, Kayange NM, Mabula JB, Alicia Massengaet A. Infantile hypertrophic pyloric stenosis at a tertiary care hospital in Tanzania: a surgical experience with 102 patients over a 5-year period. BMC Res Notes. 2015; 8:690. Available from: https://doi.org/10.1186/s13104-015-1660-4.

9. To T, Wajja A, Wales PW, Langer JC. Population demographic indicators associated with the incidence of pyloric stenosis. Arch Pediatr Adolesc Med. 2005; 159:520.

10. Taylor ND, Cass DT, Holland AJA. Infantile hypertrophic pyloric stenosis: Has anything changed? J Paediatr Child Health. 2013; 49:33-7. Available from: https://doi.org/10.1111/jpc. 12027. to conceal the identity of the patient, however it cannot be guaranteed.

Author Contributions: Author(s) declared to fulfil authorship criteria as devised by ICMJE and approved the final version.

11. Abraham C. Post-operative outcomes of oxidized regenerated cellulose use in women undergoing cesarean delivery. Gynecol Obstet Res Open J. 2017; 4:1-4. Available from: https://doi.org/10.17140/GOROJ-4-136.

12. Genyk Y, Kato T, Pomposelli JJ, Wright JJK, Sher LS, Tetens V, et al. Fibrin sealant patch (TachoSil) vs oxidized regenerated cellulose patch (Surgicel Original) for the secondary treatment of local bleeding in patients undergoing hepatic resection: A randomized controlled trial. J Am Coll Surg. 2016; 222:216-8.

13. Menovsky T, Plazier M, Rasschaert R, Maas AIR, Parizel PM, Verbeke S. Massive swelling of surgicel ${ }^{\circledR}$ fibrillar ${ }^{\mathrm{TM}}$ hemostat after spinal surgery. Case report and a review of the literature. Minim Invas Neurosurg. 2011; 54:2579. Available from: https://doi.org/10.1055/s-00311284394.

14. Kim SH, Kim SH, Yoon HS, Kim HK, Kim KS. Efficacy of

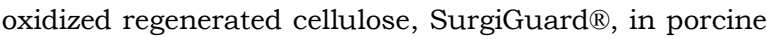
surgery. Yonsei Med J. 2017; 58:195-205.

15. Lewis KM, Spazierer D, Urban MD, Lin L, Redl H, Goppelt A. Comparison of regenerated and nonregenerated oxidized cellulose hemostatic agents. Eur Surg. 2013; 45:213-20.

16. Patanè F, Zingarelli E, Verzini A, Summa M. Complication due to excessive use of Surgicel. Eur J Cardiothorac Surg. 2001; 20:1075-6.

17. Arora ND, Varghese R, Pavithran S, Kothandam S. The pressures of surgicel ${ }^{\circledR}$ in cardiac surgery. Ann Pediatr Cardiol. 2015; 8:167-9. Available from: https://doi.org/10.4103/0974-2069.157040.

18. Brodbelt AR, Miles JB, Foy PM, Broome JC. Intraspinal oxidised cellulose (Surgicel) causing delayed paraplegia after thoracotomy - a report of three cases. Ann R Coll Surg Engl. 2002; 84:97-9. 